\title{
Using of congruent phosphate as equilibrium phosphate boilers water treatment
}

\author{
I. M. Baghni \& A. I. Zwebek \\ Engineering Academy, Tajoura, Libya
}

\begin{abstract}
Coordinated and congruent phosphates boiler water treatment has been used for more than forty years. They are very effective scale inhibitors for low and high pressure boilers. However, many steam generation units experienced such massive failures that many had to be replaced, this is mainly due to uncontrolled boiler water alkalinity. This paper describes different phosphate water treatment systems and evaluates using of congruent phosphate as equilibrium phosphate treatment. Inspection of boiler water side shows a clean surface covered with thin red powder of iron.
\end{abstract}

Keywords: corrosion, water treatment, boilers, phosphate, XRD.

\section{Introduction}

The introduction of phosphate-based boilers water treatment brought a major improvement to the development of programs based upon $\mathrm{pH}$ and free sodium hydroxide control. The application of phosphate either by itself, or in conjunction with caustic soda, it could provide the optimum $\mathrm{pH}$ necessary to minimize the corrosion of carbon steel, and to speed oxygen scavenger reaction.

In presence of hard water, phosphate also chelates or combines with calcium and magnesium ions to minimize the potential for scale deposition on the high heat flux area. The introduction of coordinated phosphate then the congruent phosphate did not improve the situation with respect to attack by caustic, it did not eliminate failures. Failures have been reported most frequently with the high-pressure boilers using de-mineralized feed water.

The aim of the present work is to evaluate medium to high pressure boilers water treatment by phosphate regimes. 


\section{Methods of boiler internal scale control}

\subsection{Carbonate control}

Before the acceptance of phosphate treatment in the 1930's, calcium sulphate scaling was a major boiler problem. Sodium carbonate treatment was used to precipitate calcium as calcium carbonate to prevent formation of calcium sulphate. As boiler temperature and pressure rose to produce more power, the calcium carbonate scale becomes unacceptable due to tubes overheating and failure.

\subsection{Coordinated phosphate}

Coordinated phosphate or captive alkalinity program was introduced by Purcell and Whirl [1] in 1943. It was the first step on the control of free hydroxide by placing an upper limit upon the alkalinity allowed relative to the phosphate concentration in boilers water as shown in fig. 1 .

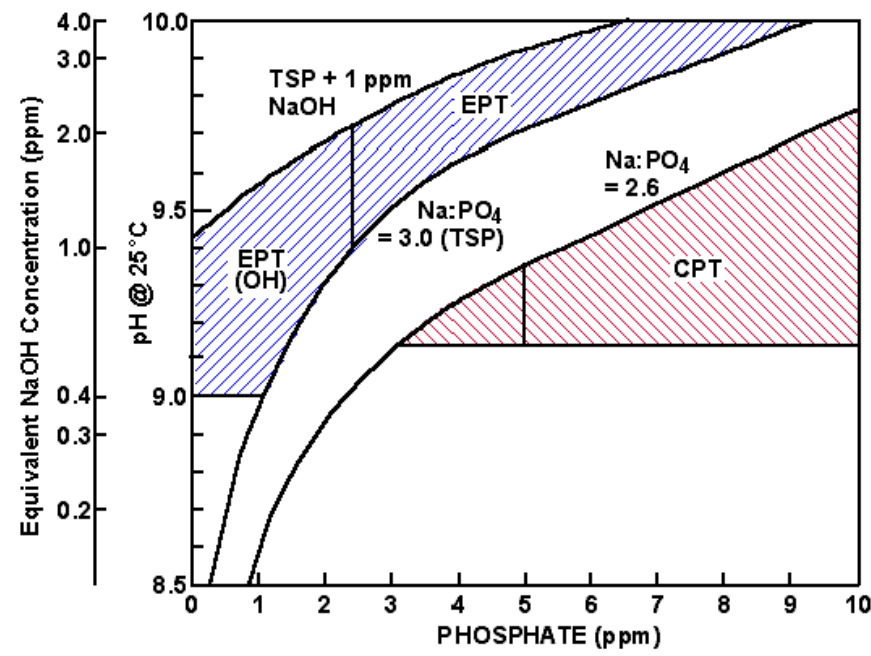

Figure 1: $\quad$ Phosphate treatment systems used in boilers [1].

The most popular treatment for low pressure boilers $(<600 \mathrm{psi})$ is dosing of tri-sodium phosphate (TSP), it reacts with water at high temperature and gives sodium hydroxide to increase boilers water $\mathrm{pH}$ as shown in equation (1).

$$
\mathrm{Na}_{3} \mathrm{PO}_{4}+\mathrm{H}_{2} \mathrm{O} \rightarrow \mathrm{Na}_{2} \mathrm{HPO}_{4}+\mathrm{NaOH}
$$

To prevent formation of free sodium hydroxide the $\mathrm{pH}$ and phosphate concentration have to be kept below the line corresponds to $\mathrm{Na} / \mathrm{PO} 4$ ratio of 3.0 found in pure tri-sodium phosphate as shown in fig. 1.

Phosphate ions react also with calcium, magnesium and iron ions to form phosphate salts, this process does not prevent the development of deposits 
accumulations over time, but the deposits can be controlled reasonably well by blow down.

If insufficient boiler water alkalinity is maintained, magnesium can combine with phosphate, magnesium phosphate formed has a surface charge that can cause it to adhere to boilers tube surfaces and then collect other solids. For this reason, alkalinity is an important part of a phosphate precipitation program.

\section{Congruent phosphate treatment}

Congruent phosphate composed of tri-sodium di-sodium and mono-sodium phosphate as will as some sodium hydroxide. The Congruent Phosphate Treatment (CPT) was first introduced by Marcy and Halstead [2] in 1964, to reduce the risk of free sodium hydroxide in boilers water, the $\mathrm{Na} / \mathrm{PO}_{4}$ ratio of this modified phosphate treatment can vary between 2.4 and 2.8 , while also maintaining the alkalinity high enough to minimize corrosion of carbon steel. The concentration of phosphate in boilers water is dependent on drum pressure and water quality, a typical high pressure boiler fed with de-mineralized water would tend to run with low concentration of 1 to $5 \mathrm{mg} / \mathrm{l} \mathrm{range,} \mathrm{while} \mathrm{a} \mathrm{lower}$ pressure boiler running with softened water might go to $25 \mathrm{mg} / \mathrm{l}$.

High alkalinity can occur either as a result of steam blanketing or by localized boiling beneath scale or porous deposits on tube surface. Steam blanketing is a condition that occurs when a steam layer forms between the boiler water and the tube wall, under this condition, insufficient water reaches the tube surface for efficient heat transfer. The water that does reach the overheated boiler wall is rapidly vaporized, and creates a concentrated phosphate and caustic solution. The supersaturated phosphate solution will enhance deposition of phosphate on internal surfaces of the boiler (which is called phosphate hideout) leaving behind a high $\mathrm{pH}$ caustic solution [3, 4]. Hideout can occur with tri-sodium phosphate or when $\mathrm{Na} \mathrm{PO}_{4}$ is more than 2.6 for boilers suffer from scale deposition, it also occurs when more phosphate is dosed to the boiler drum, that exceeds the equilibrium concentration.

In case of congruent phosphate treatment, the mechanism of alkalinity control of boilers water is based on reaction of di-sodium and mono-sodium phosphate with free hydroxide generated by tri-sodium phosphate as shown in equations (1, 2 and 3 ) to form tri-sodium phosphate. Sufficient di-sodium and mono-sodium phosphate must be available to combine with all free caustic in the boiler water, which will result in prevention of caustic build-up beneath deposits or within crevices. Mono-sodium phosphate can also lower $\mathrm{pH}$ of boilers water by generating hydrogen ions as shown in equation (4).

$$
\begin{gathered}
\mathrm{NaH}_{2} \mathrm{PO}_{4}+\mathrm{NaOH} \rightarrow \mathrm{Na}_{2} \mathrm{HPO}_{4}+\mathrm{H}_{2} \mathrm{O} \\
\mathrm{Na}_{2} \mathrm{HPO}_{4}+\mathrm{NaOH} \rightarrow \mathrm{Na}_{3} \mathrm{PO}_{4}+\mathrm{H}_{2} \mathrm{O} \\
\mathrm{NaH}_{2} \mathrm{PO}_{4}+\mathrm{H}_{2} \mathrm{O} \rightarrow 3 \mathrm{H}^{+}+\mathrm{PO}_{4}^{3-}+\mathrm{OH}^{-}+\mathrm{Na}^{+}
\end{gathered}
$$


Despite addition of di-sodium phosphate to reduce alkalinity, phosphate hideout at high heat flux area still occur that lead to a very significant shift of $\mathrm{pH}$ and phosphate concentration with load.

Since solubility of phosphate increases progressively with a drop in $\mathrm{Na} / \mathrm{PO}_{4}$ ratio below 2.0 the addition of di-sodium or mono-sodium phosphate for $\mathrm{pH}$ control could result in the formation of strongly acidic environment that will react with both magnetite film and the base metal [5], as shown in equations $(4,5$ and 6).

$$
\begin{gathered}
2 \mathrm{Na}_{2} \mathrm{HPO}_{4}+\mathrm{Fe}_{3} \mathrm{O}_{4} \rightarrow \mathrm{NaFePO}_{4}+\mathrm{Na}_{3} \mathrm{PO}_{4}+\mathrm{Fe}_{2} \mathrm{O}_{3}+\mathrm{H}_{2} \mathrm{O} \\
2 \mathrm{Na}_{2} \mathrm{HPO}_{4}+\mathrm{Fe}+\frac{1}{2} \mathrm{O}_{2} \rightarrow \mathrm{NaFePO}_{4}+\mathrm{Na}_{3} \mathrm{PO}_{4}+\mathrm{H}_{2} \mathrm{O}
\end{gathered}
$$

Concentrated sodium hydroxide can also react directly with magnetite to destroy the protective film [6].

$$
4 \mathrm{NaOH}+\mathrm{Fe}_{3} \mathrm{O}_{4} \rightarrow \mathrm{Na}_{2} \mathrm{FeO}_{2}+\mathrm{NaFeO}_{2}+2 \mathrm{H}_{2} \mathrm{O}
$$

The fact that hydrogen evolution can result from both caustic gouging and acidic phosphate attack $[7,8]$ requires a rigid operation control and a good monitoring schedule.

\section{Equilibrium phosphate treatment (EPT)}

Equilibrium phosphate control is based on boilers water treatment by tri-sodium phosphate for low pressure boilers and tri-sodium phosphate added low concentration of sodium hydroxide for high pressure boilers as shown in fig. 1 .

EPT has no specification to which the boiler must be forced to perform; it is based on determining the equilibrium concentration that can be tolerated before deposition occurs and keeping at or below that value [9]. The phosphate equilibrium value can be determined by excess addition of phosphate followed by monitoring the decay of phosphate concentration in boilers water when dosing of phosphate is stopped. The excess concentration will deposit within the system due to hideout phenomenon and it will continue to do so until the equilibrium value is reached. The phosphate, $\mathrm{pH}$ and $\mathrm{Na} / \mathrm{PO}_{4}$ ratio will remain stable with or without load change if the plant is operated near to equilibrium conditions.

It is clear that EPT can offer many benefits to the system such as less hideout phenomenon, low alkalinity and less acid phosphate corrosion.

\section{Chelant treatment}

Two chelants are widely used for boiler water treatment to keep precipitates from forming; the tetra-sodium salt of ethylene di-amine tetra-acetic acid (EDTA) and the tri-sodium salt of nitrilotriacetic acid (NTA), they both react with calcium magnesium and other heavy metals such as iron and copper and form complex compounds that can be taken out by blow down. 
High concentrations of chelants can react with the scale ions, the magnetite protective film and the base metal. This indicates a need for a stringent monitoring program to prevent the drawbacks of the treatment.

\section{Experimental procedure}

Power generation boiler working at 43 bar, generate an average 170 ton/hr steam to run steam turbine. For the first nine months sodium sulphite as oxygen scavenger was dosed in de-aerator drum to remove oxygen from demineralised feed water and tri-sodium phosphate as scale inhibitor was injected in boiler steam drum. Because of the boiler feed water low $p H$ and occasional high alkalinity values in boilers water, the treatment was changed to carbohydrazid and congruent phosphate containing $\mathrm{Na} / \mathrm{PO}_{4}$ ratio of 2.8 and $10 \%$ sodium hydroxide.

The boiler water and boiler feed water were analyzed regularly as a part of monitoring program, a typical operation limits of the second period are shown in table (1).

Table 1: Operation limits of boiler feed water and boiler water, when congruent phosphate treatment was used.

\begin{tabular}{|l|l|l|}
\hline & BFW & BW \\
\hline $\mathrm{pH}$ & $8.8-9.3$ & $9-10$ \\
\hline Conductivity $\left(\mu \mathrm{S} / \mathrm{cm}^{2}\right)$ & $1-2.6$ & $5-30$ \\
\hline $\mathrm{CHZ}(\mathrm{ppm})$ & $80-100$ & $30-50$ \\
\hline $\mathrm{O} 2(\mathrm{ppb})$ & $12-30$ & \\
\hline PO4 $(\mathrm{ppm})$ & - & $1-3$ \\
\hline Palka & - & $0.0-2$ \\
\hline M.alka & - & $4-8$ \\
\hline Turbidity & & $10-40$ \\
\hline $\mathrm{SiO}_{2}(\mathrm{ppm})$ & 0.02 & 0.04 \\
\hline $\mathrm{Fe}^{2+}(\mathrm{ppm})$ & 0.03 & $<1$ \\
\hline $\mathrm{Blow}$ down $\%$ & & $1-3$ \\
\hline
\end{tabular}

\section{Results and discussion}

The results can be presented for two phosphate systems as follows:

\subsection{Coordinated phosphate and sulphite system}

When tri-sodium phosphate is used, $98 \%$ of the salt will hydrolyse to di-sodium phosphate and sodium hydroxide according to the following reaction.

$$
\mathrm{Na}_{3} \mathrm{PO}_{4}+\mathrm{H}_{2} \mathrm{O} \rightarrow \mathrm{Na}_{2} \mathrm{HPO}_{4}+\mathrm{NaOH}
$$

Thus one mole tri-sodium phosphate will increase boiler water $\mathrm{pH}$ equivalent to one mole sodium hydroxide if boiler water $\mathrm{pH}$ is in the range of 9 to 10.0 . 
The relation between $\mathrm{pH}$ of boiler water and phosphate residue concentration is shown in fig. 2. This curve is very close to the typical tri-sodium phosphate concentration in fig. 1.

The low $\mathrm{pH}$ values of boiler water compared to phosphate residue concentration can be attributed to two factors, first, di-sodium phosphate formed has no effect on boilers $\mathrm{pH}$, and it has no ability to buffer any pollutant may inter the boiler, second, the use of sodium sulphite as oxygen scavenger in this situation will react with oxygen to produce sodium sulphate, which is a salt of strong acid.

$$
2 \mathrm{Na}_{2} \mathrm{SO}_{3}+\mathrm{O}_{2} \rightarrow 2 \mathrm{Na}_{2} \mathrm{SO}_{4}
$$

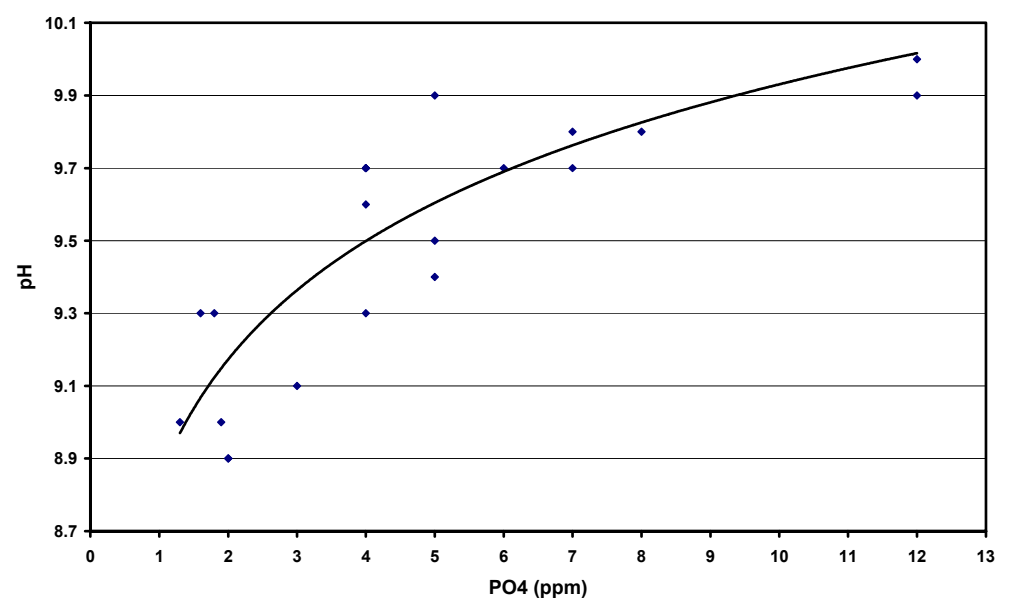

Figure 2: Phosphate concentration-pH of boiler water when using coordinated phosphate $\mathrm{Na} / \mathrm{PO}_{4}$ ratio equal 3.0.

On the other hand, if partial steam evaporation takes place in high heat flux area or especially under scale deposits, sodium di-phosphate will hide out with no revert to sodium tri-phosphate, so that the excess phosphate will deposit on the wall surface leaving behind a concentrated sodium hydroxide with high $\mathrm{pH}$ value, and this is the main cause of caustic gouging and caustic cracking in boilers using only sodium tri-phosphate.

In recent years many manufacturers of high heat flux boilers restrict $\mathrm{pH}$ in that range 9 to 9.6 and phosphate residue concentration to less than 3 ppm in boilers water. These two stringent limits can be hardly met when using sodium tri-phosphate.

The boiler water conductivity show a linear increase with phosphate concentration as indicated in fig. 3. However, some scatter of points from the main line is observed, this is mainly due to variation in blow down rates which is in the range of 1 to $3 \%$. 


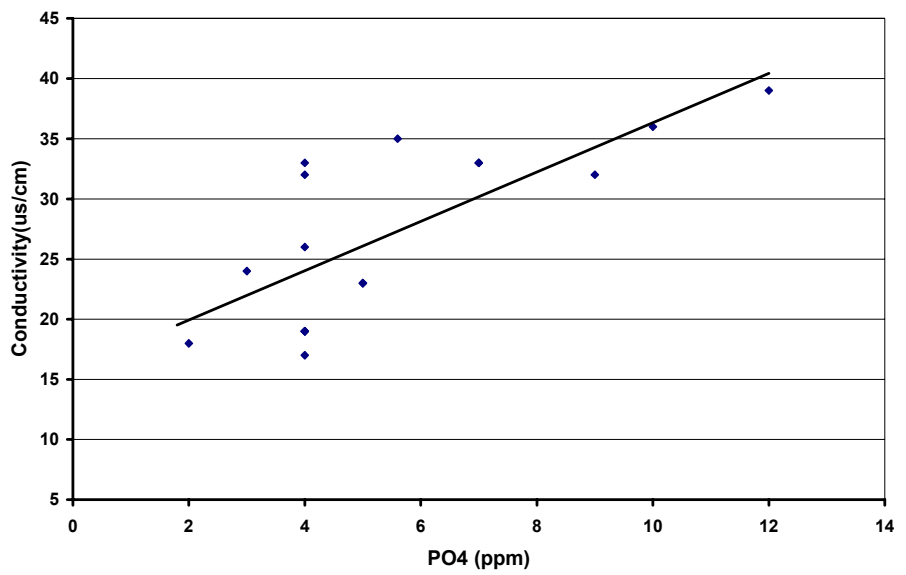

Figure 3: Conductivity and $\mathrm{pH}$ of boiler water when using tri-sodium phosphate.

The conductivity of a steady blow down rate boiler can be used to estimate phosphate concentration, which is a simple way to monitor the boiler water if there are no any pollutants in feed water.

\subsection{Congruent / Equilibrium phosphate treatment:}

Congruent phosphate used in this study is a mixture of sodium mono, di and triphosphate as well as $10 \%$ sodium hydroxide added to the solution, this represents $2.8 \mathrm{Na} / \mathrm{PO}_{4}$ ratio, the salt contained also polymer to enhance sludge conditioning.

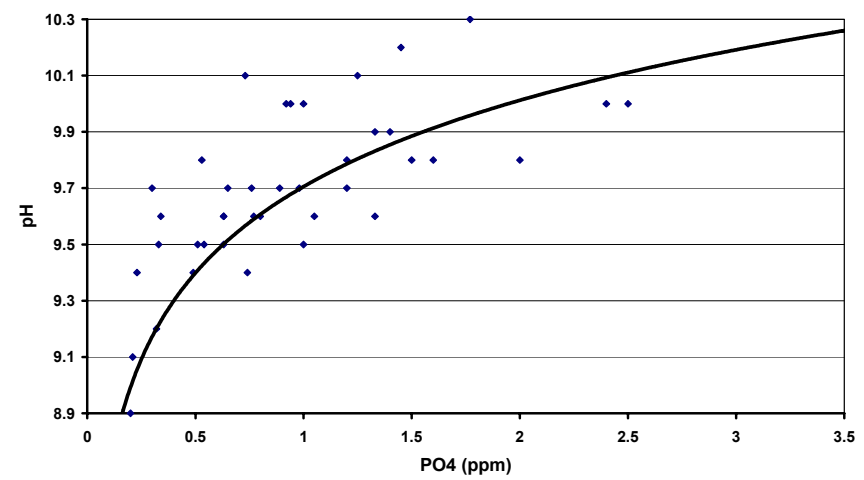

Figure 4: Phosphate concentration and $p H$ in boiler water treated with congruent phosphate.

The congruent phosphate salts in this situation is used and working in the range of equilibrium phosphate treatment, the phosphate concentration is kept 
below $3 \mathrm{ppm}$ in boilers water and $p H$ at 9 to 10.0 . The relation between phosphate concentration and boiler water $\mathrm{pH}$ is shown in fig. 4 .

Presence of mono and di-sodium phosphate is relied on to consume excess hydroxide added or formed by tri-sodium phosphate and un-used by the system. Comparing with tri-sodium phosphate in fig. 2, congruent phosphate needs less than $3 \mathrm{ppm}$ phosphate to reach $\mathrm{pH}$ of 10 . However, some points in the fig. 4 show high $\mathrm{pH}$ values for low phosphate concentration, this mains that presence of free hydroxide in the system, measurement of alkalinity indicates that for most of the cases free hydroxide ions concentration was less than $2 \mathrm{ppm}$.

Once again conductivity can be used to estimate phosphate concentration in boiler water as shown in fig 5. On the other hand due to added sodium hydroxide, the estimated phosphate from $\mathrm{pH}$ values gives higher concentrations than the actual values.

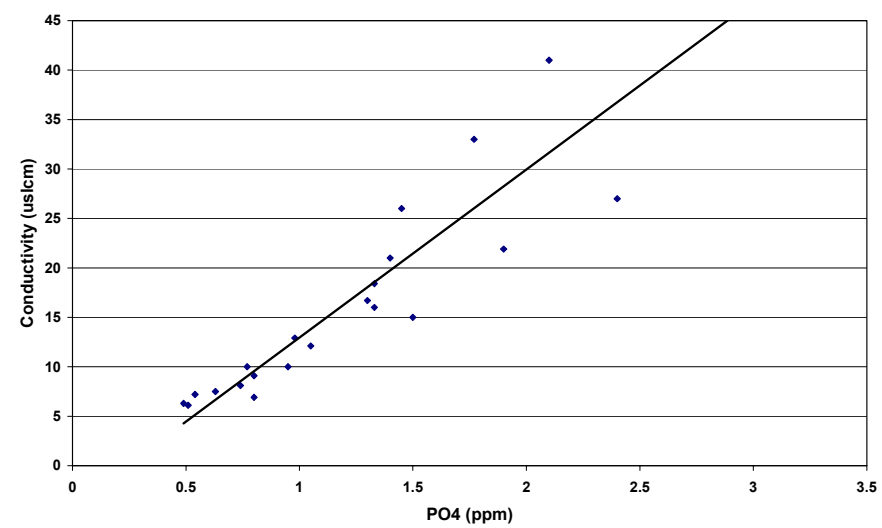

Figure 5: Conductivity of boilers water and phosphate concentration in congruent phosphate system.

\section{Boiler internal inspection}

After 28 months of operation the boiler was opened for inspection; steam drum, water drum, riser and down comer tubes show no signs of general or pitting corrosion and no scale deposition, the surface was covered by loose thin red colour revealing beneath a protective black magnetite as shown in fig. 6 , the wilding Sims also show no cracks, no corrosion or salt deposition.

It appears that congruent phosphate salts can be used to treat boilers water in the equilibrium phosphate region in case of demineralised feed water taking into account two main modifications; first reduction of sodium hydroxide added to the range of 5 to $10 \%$ in order to prevent free alkalinity in boilers water and second reduction of $\mathrm{Na} / \mathrm{PO}_{4}$ to 2.6 ratio.

When sodium hydroxide reduced to less than $10 \%$ and $\mathrm{Na} / \mathrm{PO} 4$ to 2.6 ratio there will be a buffering capacity to prevent caustic cracking and caustic gouging 
on one hand and phosphate acid attack on the other hand. Reduction of sodium hydroxide added will increase also the range of phosphate treatment with respect to $\mathrm{pH}$ for medium to high pressure boilers, and it will be more effective on chelating any ions getting into the feed water such as iron, copper or pollutants in return condensate.
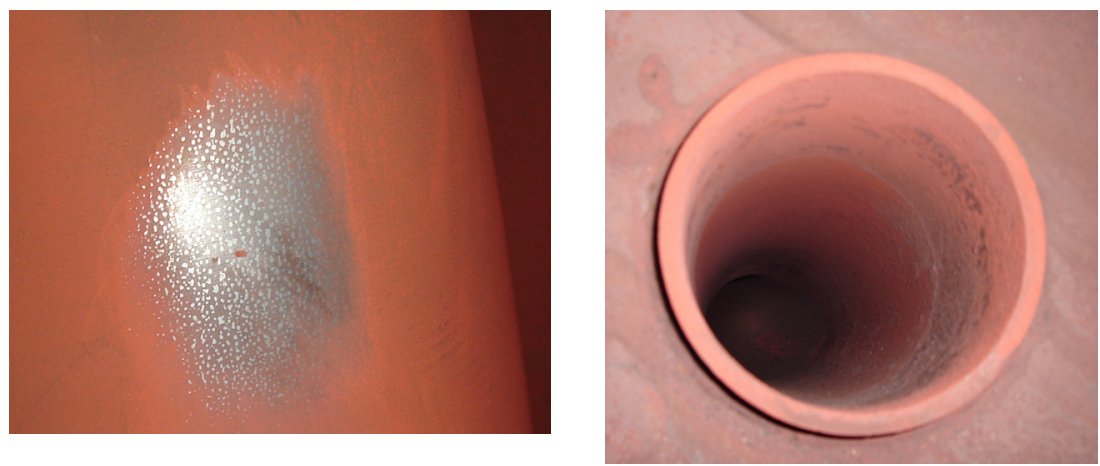

Figure 6: Steam drum and down comer tube of the boiler after 28 months of service.

\section{Red oxide analysis}

The red loos powder covering water side of the boiler was collected from the surface and analysed by X-ray diffraction, it indicates presence of $69 \%$ magnetite, $30 \%$ hematite and $5 \%$ wustite, the X-ray diffraction pattern is shown in the fig 7 .

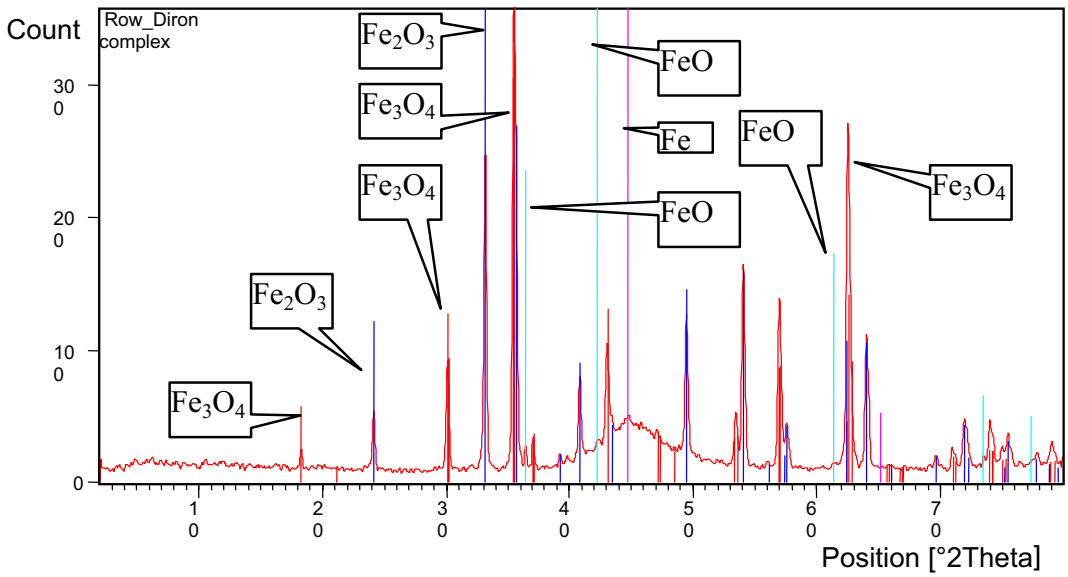

Figure 7: XRD patterns of red oxide. 
Since magnetite is thermodynamically unstable in presence of water and oxygen, it reacts with oxygen to form hematite $[10,11]$.

The XRD results suggested that some magnetite has changed to hematite and wustite when the main hole of the boiler is opened, that lets oxygen to get in and to react with the metal surface according to the following reaction.

$$
4 \mathrm{Fe}_{3} \mathrm{O}_{4}+\mathrm{O}_{2} \rightarrow 6 \mathrm{Fe}_{2} \mathrm{O}_{3}
$$

In presence of water and oxygen $\mathrm{Fe}^{2+}$ can also defuse from the magnetite $\left(\mathrm{Fe}^{2+}\right)\left(2 \mathrm{Fe}^{3+}\right) \mathrm{O}_{4}$ and react with oxygen to form Wustite $\mathrm{FeO}$.

\section{Conclusion}

Congruent phosphate salts can be modified to be used in the equilibrium phosphate region.

Reduction of added sodium hydroxide to congruent phosphate and $\mathrm{Na} / \mathrm{PO}_{4}$ ratio will prevent caustic cracking and gouging and acid phosphate attack for high pressure boilers.

The modification of the system will have more phosphate that will chelate any intruded ions to the system.

The treatment of boiler water by congruent phosphate in the equilibrium phosphate region show an effective protection of general, pitting and prevention of scale deposition.

\section{References}

[1] Purcell, T.E. and Whirl, S.F., Protection against caustic embitterment by coordinated phosphate $\mathrm{pH}$ control, Transactions of The Electrochemical Society, 83, pp279295 (1943).

[2] Marcy, V.M. and Halstead, S.L., Improved basis for coordinated phosphate pH control of boilers water, Combustion, 45, pp 4547 (1964).

[3] Economy, G. et al., Sodium phosphate solutions at boiler conditions: Solubility, phase equilibria and interactions with magnetite, Proceeding of $35^{\text {th }}$ International water Conference, pp 161173, Pittsburgh (1975.

[4] Jonas, O. and Layton, K.F., Phosphate boiler water treatment for high pressure boilers, Proceeding of Second Fossil Plant Cycle Chemistry Conference, Seattle, GS-6166, Aug(1988).

[5] Layton, K.F., Water side corrosion in the water wall tubes of hunter unit 3, Proceeding of EPRI Conference on Boiler Tube Failures in Fossil Plants, EPRI - 1890, pp2-272 to 2-286, Nov.(1987).

[6] Principles of industrial water treatment, second edition, Pub. Drew Chemical Corporate, USA, p 221(1978).

[7] Tremaine, P.R., Gray, L. and Stodola, J., Sodium phosphate chemistry under high pressure utility drum boiler conditions, Canadian Electrical Association Report 913 G730(1992). 
[8] Tremaine, P.R., et al., Phosphate interactions with metal oxides under high pressure conditions, Proceeding of $54^{\text {th }}$ International Conference, pp.186196, Pittsburgh(1993).

[9] Stodola, J., Rational for equilibrium phosphate treatment, Proceeding of International Conference on Fossil plant cycle chemistry, Baltimore, EPRI , TR100195, Electrical power research institute, Palo Alto (1991).

[10] Jing Tong et al., Magnetite Fe3O4 Nanocrystals: Spectroscopic observation of Aqueous oxidation kinetics.

[11] Umberto C. et al., Science, Vol. 147 (3661). 